\title{
Collaboration in Local Economic Development: The Case of Toledo
}

\author{
Neil Reid and Bruce W. Smith
}

Neil Reid, Department of Geography and Planning / The Urban Affairs Center, The University of Toledo, Toledo,USA (neil.reid@utoledo.edu).

Bruce W. Smith, Department of Geography / Center for Regional Development, Bowling Green State University, USA (bsmith4@bgsu.edu).

\begin{abstract}
Many American communities place a high priority on retaining and attracting innovative industries. However, in most American metropolitan areas, the responsibility for local economic development is fragmented along jurisdictional and institutional lines. The result of this fragmentation is that local economic development is often chaotic with no one individual, agency, or jurisdiction in control, which may inhibit the effectiveness of local economic development efforts. To address these challenges and more effectively utilize resources, there has been greater emphasis recently on regional collaboration in local economic development. The purpose of this paper is to measure the extent of collaboration among local economic development professionals in the Toledo, Ohio Metropolitan Statistical Area and to identify the extent to which these interactions constitute a social network. We believe that the existence of a strong social network among economic development professionals is critical to overcome some of the negative effects of jurisdictional and institutional fragmentation. While there is a core network of relatively dense collaboration in northwest Ohio, that network does not span the entire metropolitan area. A high level of local interactions occurs, but there are few "global pipelines" outside the region. A potential challenge for economic development in the region is to avoid "lock in", which will make it more difficult to attract innovative industries or diversify the economy in order to decrease the traditional dependence on the auto industry.
\end{abstract}

Keywords: innovative industries, local economic development, social networks, lock-in

\section{Introduction}

In the United States, local economic development is a function of municipal, county, and state governments (Lobao and Kraybill 2005). Because of the bottom-up approach, local economic development is fragmented along jurisdictional and institutional lines (Parker 2001). For example, in Toledo, Ohio, with a 2008 metropolitan population of 649,104 , there are over 30 organizations that claim local economic development as part of their mission.

Over the years the strategy of many economic development agencies in the U.S. has changed from recruiting businesses ('smokestack chasing') to increased emphasis on regional collaboration, including the creation of networks and clusters of industries (Malecki 2002, Shaffer et al. 2006). It also entails public and private sector actors cultivating 'soft networks' in order to acquire necessary knowledge through social interactions (Malecki 2002). Cox (1998) posited that local actors (people, local government, businesses, etc.) build networks of association, or collaborate, because they share a common goal of protecting or enhancing their place dependent interests due to their local dependence. 
Various researchers have examined the extent of collaboration among economic development organizations, using a variety of methodologies. For example, Gordon (2007) and McGuire (2000) relied on interviews with economic development agents. Olberding (2002) used survey data to ascertain the extent to which norms impact regional cooperation. These studies did not, however, directly measure the collaborative networks of economic development officials, which is the focus of this paper.

\section{Purpose}

The purpose of this paper is to analyze the extent of collaboration among economic development officials using social network analysis (SNA). SNA is used to delineate and analyze the social structure of collaborative links among economic development officials. The Toledo, Ohio Metropolitan Statistical Area (MSA) (hereafter referred to as Toledo) is the study area selected for analysis (Figure 1).

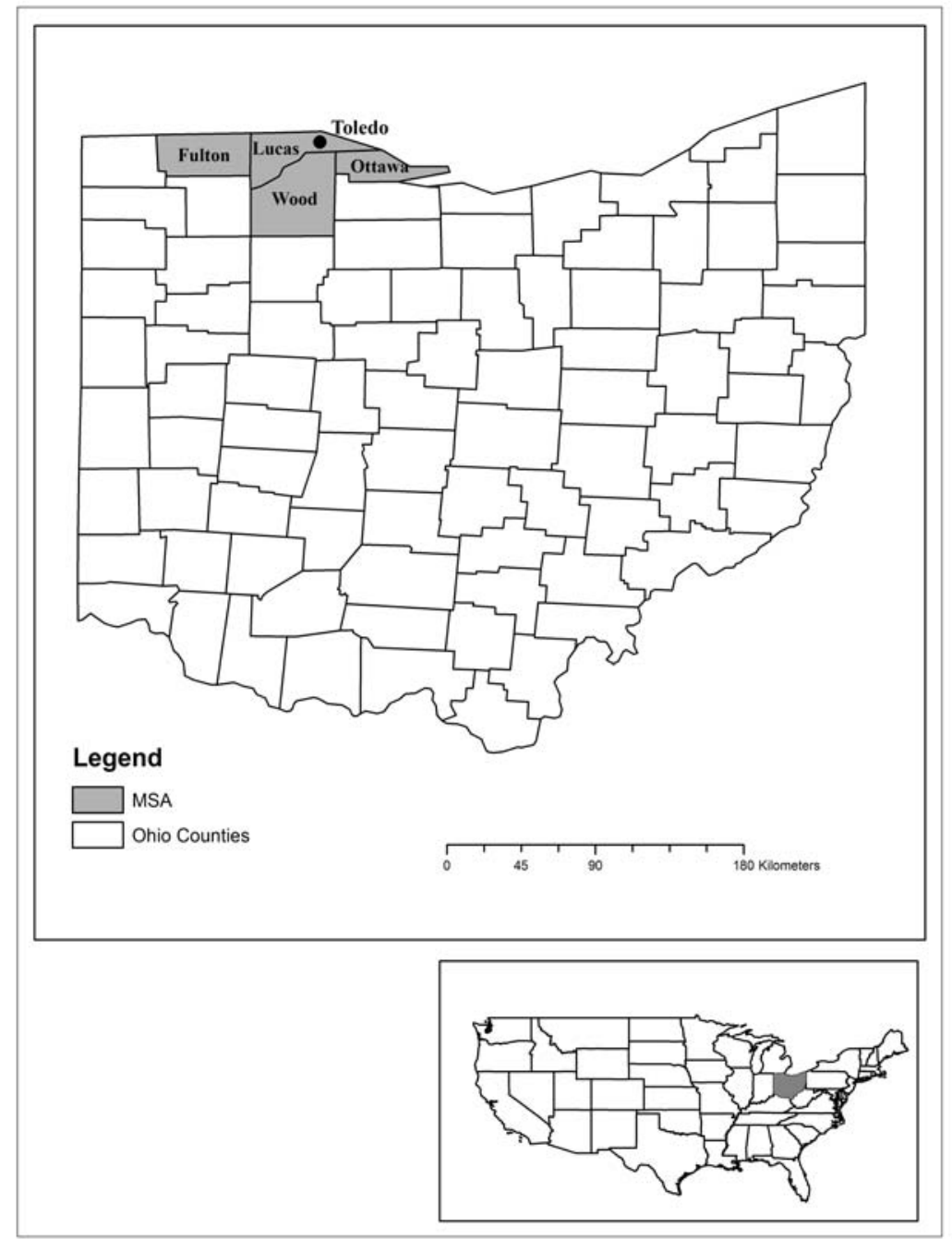

Figure 1: Study Area

MSA's are defined by the U.S. Census Bureau using counties as building blocks. The core county of an MSA is one with a large population nucleus. Surrounding counties are 
included in the MSA if they have a high degree of social and economic interaction with the core county. In effect MSAs represent functional regions. In the case of the Toledo MSA, Lucas County (2008 population of 440,456) is the core county (Census of Population 2008). This is where the city of Toledo (population 298,441) is located. Surrounding counties that are part of the Toledo MSA are Wood $(125,340)$, Fulton $(42,485)$, and Ottawa $(40,823)$ counties.

The remainder of this paper is divided into four sections. The first provides some contextual discussion on the Toledo economy and climate of collaboration. Next, the methodology of social network analysis is described. The results of the analysis are then presented. Finally, we conclude with a discussion of the implications of our findings.

\section{Economic Development in Toledo}

The growth of Toledo, similar to many other cities in the country's historical manufacturing belt, was simulated by the growth of manufacturing. However, manufacturing employment in Toledo declined by 33.3 per cent between 1980 and 2005 (County Business Patterns 2008). This has been accompanied by stagnation in population growth in the MSA, which decreased by 0.2 per cent during the same years (Census of Population 2008). Despite an absolute decline in the number of manufacturing jobs, manufacturing remains a significant component of the Toledo economy comprising 17.5 per cent of the MSA's labour force versus 11.7 per cent of the nation's.

Given the economic challenges facing the Toledo region in recent years, the overwhelming focus of the region's economic development efforts has been on retaining current jobs, creating new jobs through the expansion of current business capacity, and attracting new investment into the region. For the purposes of this study, therefore, we were specifically interested in collaborations that had job retention or creation as their primary goal. The need for strategic coordination and collaboration in the quest for jobs is a function of the large number of agencies and political jurisdictions that engage in job retention and creation efforts. As noted previously, over 30 entities (public and private) perform some type of economic development function in the Toledo area. Each of the four counties in the MSA has its own economic development office trying to attract investment to its jurisdiction. Within each county there are numerous municipalities that are also trying to attract investment. This creates a highly competitive environment that has historically resulted in a failure to use scarce economic development funds in a coordinated, strategic, and cost-effective manner. A consultant, hired to help Toledo streamline its economic development efforts, noted the gaps, overlaps, and confusion caused by the plethora of economic development entities, leading to inefficiency and under-performance (Hammer, Siler, George Associates 2004, ii).

Since the 2004 consultant's report, the inefficiencies resulting from having so many economic development entities has become a topic of serious discussion within the economic development community. There is evidence that progress is being made, however. For example, the 2005 Comprehensive Economic Development Strategy that was completed for Lucas County emphasizes the need for the various economic development stakeholders to work collaboratively on economic development initiatives (Lucas County Board of Commissioners 2005). 
To contribute to the ongoing discussion of collaboration among economic development professionals in Toledo, we conducted a social network analysis to provide the economic development community with an objective overview of the extent of collaboration between economic development professionals.

\section{Social Network Analysis}

Social network analysis (SNA) addresses relationships among a group of people and/or organizations (de Nooy et al. 2005) with the notion that social networks impact the behaviour of people and organizations. The input to a SNA is relational data, such as business transactions or social connections which link nodes (people or organizations). Moreover, SNA identifies the informal structure of relationships within an organization or region. As Cross and Parker (2004: 9) state, "whether as a manager presiding over a department or as a member embedded within one, we are all dramatically affected by information flows and webs of relationships within social networks. These networks are often not depicted on any formal chart, but they are intricately intertwined with an organization's performance, the way it develops and executes strategy, and its ability to innovate".

While SNA provides a useful methodology for analyzing social relationships, it does present some challenges. Ter Wal and Boschma (2009) provide a discussion of many of those considerations. For example, it was critical in this work that the term 'collaboration' carried the same meaning for all respondents in the survey. In developing our questionnaire, we met with several economic development officials to clarify terminology, solicit their general input to the process, and help compile a list of all economic development officials in the metropolitan region.

Data collection in SNA can be problematic (Ter Wal and Boschma 2009). First, it is a time consuming process. Moreover, SNA presumes that information on the overall network within a region can be obtained. If that is not possible, then one will have a limited perspective. Our data were collected using the roster-recall method (Ter Wal and Boschma 2009). In this approach, we first compiled a complete list of all 81 economic development officials in the region. Each of those people was given a list of all 81 persons being surveyed. They were asked to indicate those individuals with whom, over the last 12 months, they had collaborated on an economic development project. This could become a snowball sample because one could then send the questionnaire to those persons listed by respondents who were not on the initial roster. The results reported in this paper are based on the responses received from the original list of respondents. A total of 59 persons responded for a 70 per cent return rate. Those 59 respondents wrote in additional people so a total of 174 different nodes (people) emerged from the survey. With a lower response rate, one has to cautiously interpret network metrics (Brandt et al. 2009). To obtain the network metrics, InFlow 3.1 was utilized (Orgnet.com).

While SNA provides a perspective on the collaborative network among economic development officials in Northwest Ohio, it does not provide information on the role of persons in the collaboration. For example, it does not indicate which person instigated the collaboration. Nor does it indicate if people are benefiting the network or if they are engaging in opportunistic behaviour. Interviews with the people will be necessary to unpack those dynamics. In general, a combination of various methodologies may be warranted to overcome some of the challenges of SNA. 


\section{Results}

A large number of network metrics have been developed which provide information on the network structure as well as its nodes and linkages (de Nooy et al. 2005). We selected centrality of persons, density of the network, and descriptors of the geography of linkages to examine. These measures reveal the leaders and leading organizations in the collaborative network of the Toledo metropolitan region. Also they provide insights into the robustness and spatiality of the network.

\section{Centrality}

The role and influence of people depends on their position in the network which can be in part measured by centrality (Wasserman Faust 1994). Centrality can be measured in various ways. In this study, degrees-in was selected, which is the number of times that a person is mentioned by other people in the network. Because degrees-in depends in part on the size of the network, it is standardized by the number of nodes in the network. The normalized value ranges from 0 (no connections) to 1 (connections to everyone in the network,

The centrality of all persons identified by the survey was computed. In order to maintain the anonymity of the respondents, individual results cannot be reported. However, a centrality core was identified which included all the people having centrality scores more than one standard deviation above the mean. Table 1 shows selected organizations in Toledo and the number of the people in the centrality core coming from each organization. People in those organizations are the most influential leaders in forging collaboration within the economic development community.

It is apparent that the leadership in local collaboration has a diverse base involving people from ten organizations. Coulson and Ferrario (2007) suggest that a multiplicity of organizations with an economic development agenda is indicative of greater 'institutional thickness' supporting economic development. It is noteworthy that The University of Toledo (UT) has the largest number of individuals in the centrality core. This is probably reflective of the fact that, in recent years, the university has played an increasingly more visible role in the region's economic development efforts since the former and current UT Presidents have prioritized economic development in the university's mission.

It is notable that no one from Fulton or Ottawa Counties is included in the core. In addition, only one private sector business (First Energy Corporation) and one state agency (Ohio Department of Development) are represented.

Table 1: Centrality Core

\begin{tabular}{l|l}
\hline Organization & Number in Centrality Core \\
\hline University of Toledo & 6 \\
City of Toledo & 4 \\
Toledo-Lucas County Port Authority & 4 \\
Regional Growth Partnership & 4 \\
Toledo Area Chamber of Commerce & 4 \\
Lucas County Commissioners & 3 \\
Lucas County Improvement Corporation & 2 \\
First Energy Corporation & 1 \\
Local Initiatives Support Corporation & 1 \\
Ohio Department of Development & 1 \\
Wood County Economic Development Commission & 1 \\
\hline Total & 31 \\
\hline
\end{tabular}


While the SNA measures the centrality of people, it does not indicate if those people are benefiting the network or if they are bottlenecks. As Cross and Parker (2004: 73) point out, some people who are central to the network can become bottlenecks because they are overloaded with work or they intentionally position themselves to play a central role in order to have an "informational or power advantage.” Similarly, Grabher (2006: 175) suggests that networks can be used "to pursue opportunistic behaviour and to produce competition.” To evaluate these possibilities, interviews are necessary. Those interviews have not yet been conducted.

Although there are a variety of organizations in the centrality core, the underrepresentation of the private sector and non-local organizations may be problematic. Malecki (2002) argued that social interactions must be cultivated between both the private and public sectors.

\section{Density}

An important characteristic of networks is their density. Whereas the centrality metric relates to the position of people within the network, density addresses the structure of the network as a whole. One measure of density is the number of connections among nodes in the network as a percentage of the maximum number of potential connections (de Nooy et al. 2005). The density of the whole network is 4 per cent and the density of the centrality core is 44 per cent. While there are no comparable studies with which to compare these density values, obviously the core has a much higher density than the whole network. A high density in the core is desirable because the higher the density the faster information will circulate among the network members. Also a high density network is more robust. Robustness from a SNA perspective refers to the extent to which comparable levels of connectedness in the network will be maintained when nodes are removed from the network. Stated alternatively, the centrality core network has a high degree of social cohesion and social capital (de Nooy et al. 2005, Wasserman Faust, 1994).

In their methodology for empirically assessing institutional thickness, Coulson and Ferrario (2007) used density as one indicator. Their definition of density was the number of local organizations with a local economic development agenda. While their approach is reasonable, the SNA measure of density is more precise because it considers the number of interactions among agencies. The number of organizations may be misleading because the mere existence of agencies does not mean they are actively collaborating.

\section{Spatiality of Collaboration}

To further analyze the collaboration network of local economic development agents in Toledo the location of individuals mentioned in the survey were mapped. Most of the people with whom the local economic development officials collaborate were local. Only two were located outside of Ohio and over 87 per cent were located within the Toledo MSA. This local orientation is not surprising given the literature which emphasizes spatial proximity in the exchange of tacit knowledge (Morgan 2004, Storper Venables 2004). Bathelt et al. (2004) termed these local interactions as 'local buzz', which refers to the learning, interaction, and collaboration generated by routine activities, such as regular meetings, chance encounters, social outings, etc.

Despite the importance of 'local buzz', a network also needs links to the outside world. These outside links, or 'global pipelines', are communication channels to 
partners outside the local region (Bathelt et al. 2004). Such connections are sources of new ideas and collaborations as well as a fresh outlook in problem solving. The new knowledge will offset the problems of lock-in which can result in the same old solutions to challenges being recycled with the result that development choices are constrained, leading to stagnation or decline (Maskell and Malmberg 2007).

One might argue that distance will constrain collaboration on projects, so it is reasonable to expect that most of the collaboration links will be local. In the survey, respondents were also asked to indicate those people from whom they had received new ideas over the previous year. There were three people in that network who were not in the collaboration network, and all of them were local. This further substantiates the local bias in the information networks of economic development officials.

Although there is substantial interaction among economic development professionals in Toledo, the collaboration tends not to cross county lines in the metropolitan region. To gauge intra-metropolitan collaboration, we computed an external/internal (E/I) ratio for the counties constituting the MSA. The E/I ratio measures the internal or external orientation of a group or region. A group which is totally internally oriented, or closed, will have a ratio of -1 . In contrast, a ratio of 1 is indicative of all interactions occurring outside the group, whereas a 0 is the result of a balance between internal and external links. Lucas and Wood Counties, which have the most nodes, showed strongest tendencies to an internal orientation, with ratios of -0.86 and -0.15 respectively. Also Fulton County is internally oriented, with a ratio of -0.80 . Ottawa County has the most balanced collaboration pattern with a ratio of 0.0. Even though Ottawa is more balanced in terms of the ratio of external to internal collaborations, the absolute number of collaborative links between people in the other counties and economic development professionals in Ottawa County is very small.

In general the spatial distribution of collaborative links in the Toledo MSA demonstrate 'local buzz'. However, the absence of more external links may prove problematic. Also the patterns suggest that collaboration across county lines is less common than intra-county interaction. In particular, Ottawa County does not seem to be integrated into the metropolitan collaboration network.

\section{Discussion and Conclusion}

Economic development in the Toledo MSA is highly fragmented with a large number of agencies focusing, in part or totally, on economic development. Nonetheless, the SNA of the collaboration network revealed that there is substantial local collaboration. Moreover, collaboration is increasingly being emphasized by various economic development agencies.

The results of the SNA suggest that collaboration could be expanded beyond the boundaries of Lucas County, in which Toledo is located. While there is substantial interaction with people in Wood County, the same level of collaboration does not extend throughout the metropolitan area. Indeed, one could argue that such endeavours should expand beyond the metropolitan area to a larger segment of northwestern Ohio, and should even extend into neighbouring southeastern Michigan. In the same vein, the role of the private sector could be expanded.

Olberding (2002) reported that past regional cooperation is related to the formation of regional partnerships. The history of regional cooperation in the study area has been uneven. However, Olberding (2002) also suggests that strong regional need may supersede past behaviours. Most of northwestern Ohio is experiencing the same 
economic difficulties as the Toledo MSA. Consequently the key actors may be more amenable to collaboration in the future than in the past. That willingness is evidenced by the fact that in December 2007 Dan Johnson, the President Emeritus and University Professor of Public Policy and Economic Development at the University of Toledo, brought together the region's major economic development agencies. The purpose of this meeting was for agencies to share information on their economic development initiatives and to identify new opportunities for collaborative efforts.

One problem in prescribing appropriate action steps is that researchers do not concur on the optimum configuration of a network (Ahuja 2000). As one example, Coleman (1988) believes that a dense interconnected network is best, whereas Burt (2005) believes that a more open network leads to brokerage opportunities. Irrespective of one's perspective on these issues, the Toledo region's collaboration network may benefit from someone assuming the role of a network weaver (Krebs and Holley 2006) whose function would be to bridge gaps in the collaboration network. That individual should particularly focus on the inclusion of private sector people as well as people from throughout the metropolitan region. In addition, linkages outside Northwest Ohio and Ohio should be expanded.

Future research on this topic will entail interviews to better understand the nature of collaboration. Centrality is based on position within the network which denotes very little about the nature of relations among persons in the network. Interviews are necessary to unpack those relationships in order to better understand the collaborative nature of relationships within the economic development community. Another important issue that was not addressed in this study is the outcome of collaboration. Is it an effective strategy for generating local economic development? That will be the subject of future research.

\section{References}

Ahuja, G. 2000. Collaboration networks, structural holes, and innovation: A longitudinal study. Administrative Science Quarterly, 45(3), 425-455.

Bathelt, H., Malmberg, A. and Maskell, P. 2004. Clusters and knowledge: Local buzz, global pipelines and the process of knowledge creation. Progress in Human Geography, 28(1), 31-56.

Brandt, A., Hahn, C., Krätke, S. and Kiese, M. 2009. Metropolitan regions in the knowledge economy: network analysis as a strategic information tool. Tijdschrift voor Economische en Sociale Geografie, 100(2), 236-249.

Burt, R. 2005. Brokerage \& Closure. New York: Oxford University Press.

Coleman, J. 1988. Social capital in the creation of human capital. American Journal of Sociology, 94, 95-120.

Coulson, A. and Ferrario, C. 2007. Institutional thickness: Local governance and economic development in Birmingham, England. International Journal of Urban and Regional Research, 31(1), 591-615.

Cox, K. 1998. Spaces of dependence, spaces of engagement and the politics of scale, or: Looking for local politics. Political Geography, 17(1), 1-23.

Cross, R. and Parker, A. 2004. The Hidden Power of Social Networks. Boston: Harvard Business School Press.

de Nooy, W., Mrvar, A. and Batagelj, V. 2005. Exploratory Network Analysis with Pajek. Cambridge: Cambridge University Press. 
Gordon, V. 2007. Partners or competitors? Perceptions of regional economic development cooperation in Illinois. Economic Development Quarterly, 21(1), 60-78.

Grabher, G. 2006. Trading routes, by passes, and risky intersections: Mapping the travels of 'networks' between economic sociology and economic geography. Progress in Human Geography, 30(2), 163-189.

Hammer, Siler, George Associates 2004. Toledo-Lucas County Economic Development and Innovation Plan. Denver: Hammer, Siler, George Associates.

Krebs, V. and Holley, J. 2006. Building Smart Communities through Network Weaving. Available online at: http://www.orgnet.com/BuildingNetworks.pdf [accessed: 14 June 2010].

Lobao, L. and Kraybill, D. 2005. The emerging roles of county governments in metropolitan and nonmetropolitan areas: Findings from a national survey. Economic Development Quarterly, 19(3), 245-259.

Lucas County Board of Commissioners 2005. Working Together for our Future: Lucas County Comprehensive Economic Development Strategy. Toledo, OH: Lucas County Board of Commissioners.

Malecki, E. 2002. Hard and soft networks for urban competitiveness. Urban Studies, 39(5-6), 929-945.

Maskell, P., and Malmberg, A. 2007. Myopia, knowledge development and cluster evolution. Journal of Economic Geography, 7(5), 603-618.

McGuire, M. 2000. Collaborative policy making and administration: The operational demands of local economic development. Economic Development Quarterly, 14(3), 278-291.

Morgan, K. 2004. The exaggerated death of geography: Learning, proximity and territorial innovation systems. Journal of Economic Geography, 4(1), 3-21.

Olberding, J. 2002. Does regionalism beget regionalism? The relationship between norms and regional partnerships for economic development. Public Administration Review, 62(4), 480-491.

Parker, P. 2001. Local-global partnerships for high-tech development: Integrating topdown and bottom-up models. Economic Development Quarterly, 15(2), 149167.

Shaffer, R., Deller, S., and Marcouiller, D. 2006. Rethinking community economic development. Economic Development Quarterly, 20(1), 59-74.

Storper, M. and Venables, A. 2004. Buzz: Face-to-face contact and the urban economy. Journal of Economic Geography, 4(4), 351-370.

Ter Wal, A. and Boschma, R. 2009. Applying social network analysis in economic geography: Framing some key analytic issues. The Annals of Regional Science, 43(3), 739-756.

U.S. Census Bureau (various years). Census of Population.

Available online at: http://www.census.gov/main/www/cen2000.html [accessed: 14 June 2010].

U.S. Census Bureau (various years). County Business Patterns.

Available online at: http://www.census.gov/epcd/cbp/view/cbpview.html [accessed: 14 June 2010].

Wasserman, S. and Faust, K. 1994. Social Network Analysis: Methods and Applications. Cambridge: Cambridge University Press. 